Cochrane Database of Systematic Reviews

\title{
Electromagnetic therapy for treating pressure ulcers (Review)
}

Aziz Z, Bell-Syer SEM

Aziz Z, Bell-Syer SEM.

Electromagnetic therapy for treating pressure ulcers.

Cochrane Database of Systematic Reviews 2015, Issue 9. Art. No.: CD002930.

DOI: 10.1002/14651858.CD002930.pub6. 
TABLE OF CONTENTS

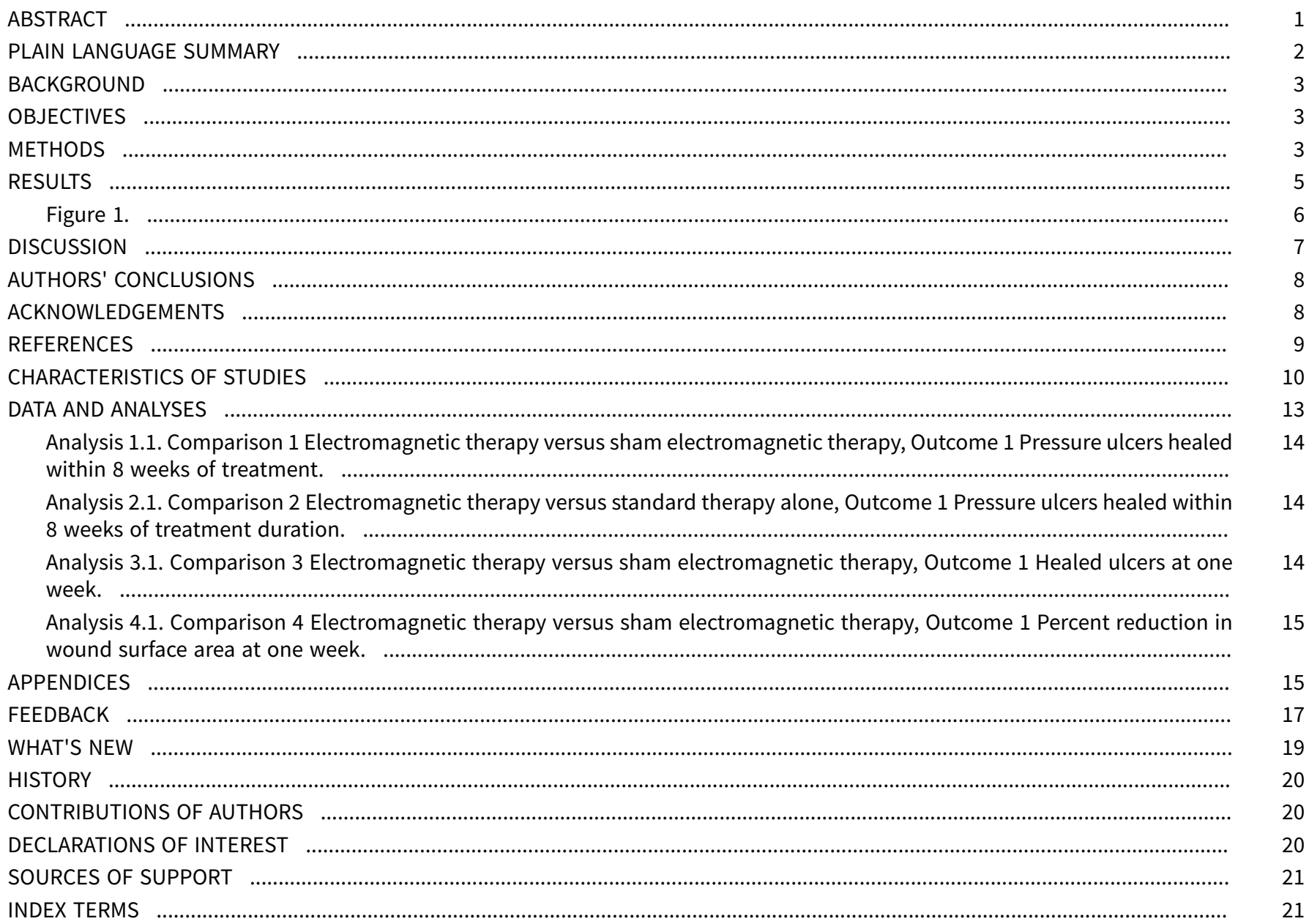


[Intervention Review]

\section{Electromagnetic therapy for treating pressure ulcers}

Zoriah Aziz¹, Sally EM Bell-Syer²

1Department of Pharmacy, Faculty of Medicine, University of Malaya, Kuala Lumpur, Malaysia. 2Department of Health Sciences, University of York, York, UK

Contact: Zoriah Aziz, Department of Pharmacy, Faculty of Medicine, University of Malaya, Kuala Lumpur, 50603, Malaysia. zoriah@um.edu.my.

Editorial group: Cochrane Wounds Group.

Publication status and date: New search for studies and content updated (no change to conclusions), published in Issue 9, 2015.

Citation: Aziz Z, Bell-Syer SEM. Electromagnetic therapy for treating pressure ulcers. Cochrane Database of Systematic Reviews 2015, Issue 9. Art. No.: CD002930. DOI: 10.1002/14651858.CD002930.pub6.

Copyright () 2015 The Cochrane Collaboration. Published by John Wiley \& Sons, Ltd.

\section{A B S T R A C T}

\section{Background}

Pressure ulcers are defined as areas "of localized damage to the skin and underlying tissue caused by pressure, shear, friction and/or the combination of these". Electromagnetic therapy (EMT), in which electrodes produce an electromagnetic field across the wound, may improve healing of chronic wounds such as pressure ulcers.

\section{Objectives}

To assess the effects of EMT on the healing of pressure ulcers.

\section{Search methods}

For this update we searched the Cochrane Wounds Group Specialised Register (searched 10 June 2015); The Cochrane Central Register of Controlled Trials (CENTRAL) (The Cochrane Library 2015, Issue 6); Ovid MEDLINE (2014 to 10 June 2015); Ovid MEDLINE (In-Process \& Other Non-Indexed Citations, 10 June 2015); Ovid EMBASE (2014 to 10 June 2015); and EBSCO CINAHL (2014 to 6 July 2012).

\section{Selection criteria}

Randomised controlled trials comparing EMT with sham EMT or other (standard) treatment.

\section{Data collection and analysis}

For this update two review authors independently scrutinised the results of the search to identify relevant RCTs and obtained full reports of potentially eligible studies. In previous versions of the review we made attempts to obtain missing data by contacting study authors. A second review author checked data extraction and disagreements were resolved after discussion between review authors.

\section{Main results}

We identified no new trials for this update.Two randomised controlled trials (RCTs), involving 60 participants, at unclear risk of bias were included in the original review. Both trials compared the use of EMT with sham EMT, although one of the trials included a third arm in which only standard therapy was applied. Neither study found a statistically significant difference in complete healing in people treated with EMT compared with those in the control group. In one trial that assessed percentage reduction in wound surface area, the difference between the two groups was reported to be statistically significant in favour of EMT. However, this result should be interpreted with caution as this is a small study and this finding may be due to chance. Additionally, the outcome, percentage reduction in wound area, is less clinically meaningful than complete healing. 


\section{Authors' conclusions}

The results provide no strong evidence of benefit in using EMT to treat pressure ulcers. However, the possibility of a beneficial or harmful effect cannot be ruled out because there were only two included trials, both with methodological limitations and small numbers of participants. Further research is recommended.

\section{PLAIN LANGUAGE SUMMARY}

\section{Electromagnetic therapy for treating pressure ulcers}

Pressure ulcers (also called bed sores, decubitus ulcers or pressure sores) are sores on the skin caused by pressure or rubbing. They usually affect immobile people on the bony parts of their bodies such as hips, heels and elbows, and take a long time to heal. Electromagnetic therapy is not a form of radiation or heating, but uses an electromagnetic field with the aim of stimulating healing. However, the review of trials concluded that there is no strong evidence that electromagnetic therapy helps or hinders healing of pressure ulcers. 


\section{B A C K G R O U N D}

\section{Description of the condition}

According to the European Pressure Ulcer Advisory Panel (EPUAP) and National Pressure Ulcer Advisory Panel (NPUAP), a pressure ulcer (also known as bed sore, bed ulcer, decubitus ulcer or pressure sore) is "an area of localized injury to the skin and/or underlying tissue usually over a bony prominence, as a result of pressure, or pressure in combination with shear" (EPUAP-NPUAP 2009). Pressure ulcers usually develop on skin that covers bony areas such as the sacrum, heels, hips and elbows. Most often the ulcers develop in immobile elderly people (for example, elderly orthopaedic patients), patients with severe, acute illnesses (such as in people in intensive care units) and in people with neurological problems (for example, those with spinal cord injuries).

One cross-sectional European study involving five countries found that the overall prevalence of pressure ulcers was approximately $18 \%$ of hospital patients (EPUAP 2002). In the UK, pressure ulcers have been recorded in $5 \%$ to $32 \%$ of patients admitted to a District General Hospital (the precise rate depends on case-mix), and in $4 \%$ to $7 \%$ of patients in community settings (Kaltenthaler 2001). These ulcers represent a major burden of sickness and reduce quality of life for patients and their carers. There is also a considerable cost both to the patients (Clark 1994) and the health service (Touche Ross 1993). The annual treatment cost of pressure ulcers has been estimated to range from $£ 1.4$ to 2.1 billion, or $4 \%$ of total healthcare expenditure in the UK (Bennett 2004).

Pressure ulcers present as a continuum of tissue damage from unbroken skin with sustained redness after the release of pressure (non-blanching erythema) to destruction of the muscle and bone.

The treatment of pressure ulcers has four main elements:

1. local treatment of wounds using wound dressings and other topical applications;

2. pressure relief using beds, mattresses or cushions, and repositioning of the patient;

3. treatment of concurrent conditions that may delay healing, e.g. poor nutrition and infection; and

4. use of physical therapies, such as electrical stimulation, ultrasound and laser therapy.

\section{Description of the intervention}

Recently there has been an increasing interest in the therapeutic use of electromagnetic fields for various medical conditions, including pressure ulcers (Markov 2007). Electromagnetic therapy (EMT), also known as electromagnetism, bioelectricity, magneto biology, magnetic healing and magnetic field therapy, uses electromagnetic energy applied to the body to treat various medical conditions, from bone and cartilage repair (Haddad 2007; Ryaby 1998) to pain relief (Shupak 2006; Thomas 2007), wound healing (Comorosan 1993; Kenkre 1996; Stiller 1992) and relatively new applications such as chronic musculoskeletal pain (Thomas 2007). EMT does not use direct electrical effects or radiation, unlike other forms of electrotherapy, but induces a field effect (Stiller 1992). A number of devices (e.g. Diapulse ${ }^{\circledR}$, SoffPulse ${ }^{\circledR}$, Pulsatron $^{\circledast}$ ) have been constructed to deliver a pulsed electromagnetic field (PEMF) in the radio frequency band. The frequency of short- wavelength radio waves ranges from 10 to $100 \mathrm{MHz}$ and the frequency commonly used in EMT is $27.12 \mathrm{MHz}$.

PEMFs are produced with an "on-off" effect of pulsing current to produce effects which, it has been suggested, influence many biological processes, and thus may be useful for wound healing. The main advantage of PEMF compared with continuous fields is that the short duration of the pulses protects the tissues against potential damage from heat generated by continuous fields (Athanasiou 2007; Kitchen 2002).

\section{How the intervention might work}

There are several theories that explain how the PEMF may exert its effect on tissue generation and cell proliferation in wound healing. Lee 1993 suggested that PEMF might facilitate the migration of electrically charged cells involved in repairing the wound area, thereby restoring the metabolic conditions of the healing cells. It has also been proposed that PEMF induces a tiny electrical signal on the injured cell membrane, which initiates a series of physiological effects that include an increase in the number of macrophages and fibroblasts present in the wound, a reduction of the inflammation and an increased deposition of collagen and fibrin, all of which contribute to the healing process (Markoll 2003). Other theories suggest that PEMF is associated with the production of free radicals within cells, which mediate intracellular communication (Gordon 2007). PEMF may exert several biological processes involved in wound healing, but the exact mechanism is not clear.

\section{Why it is important to do this review}

There are several anecdotal reports of the beneficial effects of EMT for chronic skin wounds, despite the lack of standardisation of the PEMF devices in terms of type, duration, frequency, intensity and length of exposure. A systematic review to assess the available evidence for EMT on pressure ulcers was warranted.

\section{OBJECTIVES}

To assess the evidence for the effects of electromagnetic therapy (EMT) in the healing of pressure ulcers.

\section{METHODS}

\section{Criteria for considering studies for this review Types of studies}

We included trials if the allocation of participants to the therapies was described as randomised. There was no restriction on the basis of language, date of trial or publication status.

\section{Types of participants}

We included studies which involved people of any age and in any care setting, described as having a pressure ulcer. Studies which referred to the wounds using the synonyms decubitus, bed sore and pressure sore were also eligible for inclusion.

\section{Types of interventions}

The application of EMT to treat pressure ulcers compared with sham EMT, no EMT or other (standard) treatments. 


\section{Types of outcome measures}

\section{Primary outcomes}

Healing of pressure ulcer using measures such as:

- proportion of ulcers healed within trial period;

- rate of change in ulcer area; and

- time to complete healing.

\section{Secondary outcomes}

- Costs.

- Quality of life.

- Pain.

- Acceptability of treatment.

\section{Search methods for identification of studies}

\section{Electronic searches}

Details of the search strategy for fourth update of this review are shown in Appendix 1.

For this update, we searched the following databases to find reports of randomised controlled trials (RCTs) of EMT:

- Cochrane Wounds Group Specialized Register (Searched 10/06/15)

- The Cochrane Central Register of Controlled Trials (CENTRAL) The Cochrane Library 2015, Issue 6

- Ovid MEDLINE \& Ovid MEDLINE - In-Process \& Other Non-Indexed Citations 2014 to 10 June 2015

- Ovid EMBASE - 2014 to 10 June 2015

- EBSCO CINAHL - 2014 to 10 June 2015

The following search strategy was used in the Cochrane Central Register of Controlled Trials (CENTRAL):

\#1 MeSH descriptor Electromagnetics explode all trees \#2 MeSH descriptor Electric Stimulation Therapy explode all trees \#3 (electromagnetic ${ }^{\star}$ or electrotherap ${ }^{\star}$ ):ti,ab,kw

\#4 (electric* NEXT current):ti,ab,kw

\#5 ((direct or pulsed or alternating) NEXT current):ti,ab,kw

\#6 (low NEXT intensity) or (low NEXT frequency):ti,ab,kw

\#7 (high NEXT voltage):ti,ab,kw

\#8 ("TENS" or "NMES"):ti,ab,kw

\#9 (interferential NEXT therap*):ti,ab,kw

\#10 (monophasic or galvanic):ti,ab,kw

\#11 MeSH descriptor Diathermy explode all trees

\#12 MeSH descriptor Microwaves explode all trees

\#13 (diathermy or microwave*):ti,ab,kw

\#14 (\#1 OR \#2 OR \#3 OR \#4 OR \#5 OR \#6 OR \#7 OR \#8 OR \#9 OR \#10

OR \#11 OR \#12 OR \#13)

\#15 MeSH descriptor Pressure Ulcer explode all trees

\#16 pressure NEXT (ulcer* or sore*):ti,ab,kw

\#17 decubitus NEXT (ulcer* or sore ${ }^{\star}$ ):ti,ab,kw

\#18 (bed NEXT sore ${ }^{\star}$ ) or bedsore:ti,ab,kw

\#19 (\#15 OR \#16 OR \#17 OR \#18)

\#20 (\#14 AND \#19)

The search strategies for Ovid MEDLINE, Ovid EMBASE and EBSCO CINAHL can be found in Appendix 2; Appendix 3 and Appendix 4 respectively. The Ovid MEDLINE search was combined with the Cochrane Highly Sensitive Search Strategy for identifying randomised trials in MEDLINE: sensitivity- and precisionmaximizing version (2008 revision); Ovid format (Lefebvre 2011). The EMBASE and CINAHL searches were combined with the trial filters developed by the Scottish Intercollegiate Guidelines Network (SIGN 2010). There were no restrictions on the basis of language or date of publication.

\section{Searching other resources}

For the original review and the first update, experts in the field (e.g. SA Cooper-Vastola) and manufacturers (Diapulse ${ }^{\circledR}$ and Elmedistraal ${ }^{\oplus}$ ) were also contacted and asked to provide any information they might have about unpublished studies. In the second update we checked the reference list of the systematic review by McGaughey 2009 for additional studies. No other resources were searched for this update.

\section{Data collection and analysis}

\section{Selection of studies}

For this review update, two review authors independently checked titles and abstracts of studies identified by the update search for eligibility. We obtained full reports of articles if they appeared to satisfy, or to potentially satisfy, the inclusion criteria. Two review authors independently checked full papers to identify those trials that were eligible for inclusion. Any disagreement was resolved by discussion between the two review authors.

For the original review, titles and abstracts of studies identified by searching the Wounds Group Specialised Register were assessed by one review author (KF) for eligibility. Full reports of articles were obtained if they appeared to satisfy the inclusion criteria of the initial assessment. Those rejected were checked by another review author (NC). Full papers were checked to identify those that were eligible for inclusion (KF). This was repeated independently by another review author (NC) to provide verification. Any disagreement was resolved by discussion.

\section{Data extraction and management}

We extracted and summarised details of the eligible studies using a data extraction sheet. We made attempts to obtain any missing data by contacting the trial authors. We included data from studies published in duplicate only once. One review author undertook data extraction and the second author checked for accuracy. We extracted the following data:

1. design of study;

2. inclusion and exclusion criteria;

3. baseline characteristics (by treatment group);

4. intervention details;

5. outcome measures used;

6. results (by treatment group);

7. withdrawals (by treatment group); and

8. adverse effects.

\section{Assessment of risk of bias in included studies}

Two review authors independently assessed the risk of bias of the included studies. As recommended by the Cochrane Handbook for Systematic Reviews of Interventions (Higgins 2011), we assessed the following methodological domains: 
- Sequence generation - was the method used to generate the allocation sequence appropriate to produce comparable groups?

- Allocation sequence concealment - was the method used to conceal the allocation sequence appropriate to prevent the allocation being known in advance of, or during, enrolment?

- Blinding of participants, personnel and outcome assessors were measures used to blind study participants, personnel and outcome assessors from knowledge of which intervention a participant received?

- Incomplete outcome data - how complete were the outcome data for the primary outcomes? Were drop-out rates and reasons for withdrawal reported? Were missing data imputed appropriately? We considered an overall completion rate of $80 \%$ or higher as having a low risk of bias.

- Selective outcome reporting - were appropriate outcomes reported and were any key outcomes missing?

- Other potential threats to validity (considering external validity, e.g. relevant use of co-interventions) - what was the funding source of each of the studies?

We explicitly judged each of these criteria using the following system: Yes (i.e. low risk of bias); No (i.e. high risk of bias); and Unclear (i.e. either lack of information, or uncertainty over the potential for bias).

\section{Data synthesis}

We combined the studies included in the review by narrative overview with a quantitative summary of the result of similar trials where appropriate. For each trial with important dichotomous outcomes(e.g. ulcers healed - yes or no) we calculated a risk ratio of healing with $95 \%$ confidence intervals $(\mathrm{Cl})$. Where outcomes for continuous variables were presented as medians without confidence intervals, standard deviations or some measure of the precision of the result, we entered the median into the table of Characteristics of included studies and did not use the data in data synthesis.

\section{RE S U L T S}

\section{Description of studies}

No new reports were identified in this review update. Searches for the third review update identified four additional studies (Goldin 1981; Gupta 2009; Itoh 1991; Seaborne 1996) but none met the inclusion criteria and all were added to the Characteristics of excluded studies where reasons for exclusion are provided.

Two studies of EMT for the treatment of pressure ulcers, involving a total of 60 people, are included in the review (Comorosan 1993; Salzberg 1995). The first study (Comorosan 1993) was conducted in a social care unit in Bucharest, Romania. This study was a three-arm study; EMT (plus standard therapy), sham EMT (plus standard therapy) and standard therapy alone. The treatment and follow up was over a two to eight-week period. A total of 30 people were recruited: 17 female and 13 male, aged from 60 to 84 years, with Satge II (16 participants) and Stage III (14 participants) pressure ulcers (the grading system used was not described). Participants were described as randomly allocated to one of the three groups. Twenty people received EMT (Diapulse ${ }^{\circledR}$ ) therapy plus standard therapy; five received sham EMT (Diapulse ${ }^{\circledR}$ ) therapy plus standard therapy; and five received standard therapy alone. The EMT therapy involved local application of electromagnetic field at a frequency of 600 pulses per second, peak power 6 (117 V, $27.12 \mathrm{MHz}$ ). Treatment was given for 30 minutes, twice a day. The standard therapy involved cleansing with hydrogen peroxide and local application of talcum powder, methylene-blue in solution and antibiotic ointment (tetracycline). The outcome assessed was the percentage of ulcers healed within two to eight weeks.

The second study (Salzberg 1995) compared EMT with sham EMT over a 12-week period or until healing (if this was shorter than 12 weeks). The participants were volunteers admitted to a Veterans' Administration Hospital in New York and consisted of 30 male hospital inpatients with spinal cord injuries (20 with Stage II and 10 with Stage III pressure ulcers). The treatment with an electromagnetic field provided a radio frequency of $27.2 \mathrm{MHz}$ and a pulse repetition rate of 80 to 600 pulses per second. This study also gave treatment for 30 minutes twice a day. A clear definition of the grading of the ulcers was provided by the authors: Stage II ulcers were defined as a partial-thickness skin loss involving epidermis or dermis, superificial and clinically presenting as a deep crater, abrasion, blister or shallow crater; while Stage III were defined as full-thickness skin loss involving damage or necrosis of subcutaneous tissue extending down to, but not through, underlying fascia, clinically presented as a deep crater with or without undermining of adjacent tissue. The outcomes assessed were time to complete healing, percent change in ulcer area and proportion of ulcers healed.

\section{Risk of bias in included studies}

The risk of bias in the included studies is summarised in Figure 1. 
Figure 1. Methodological quality summary: review authors' judgements about each methodological quality item for each included study.

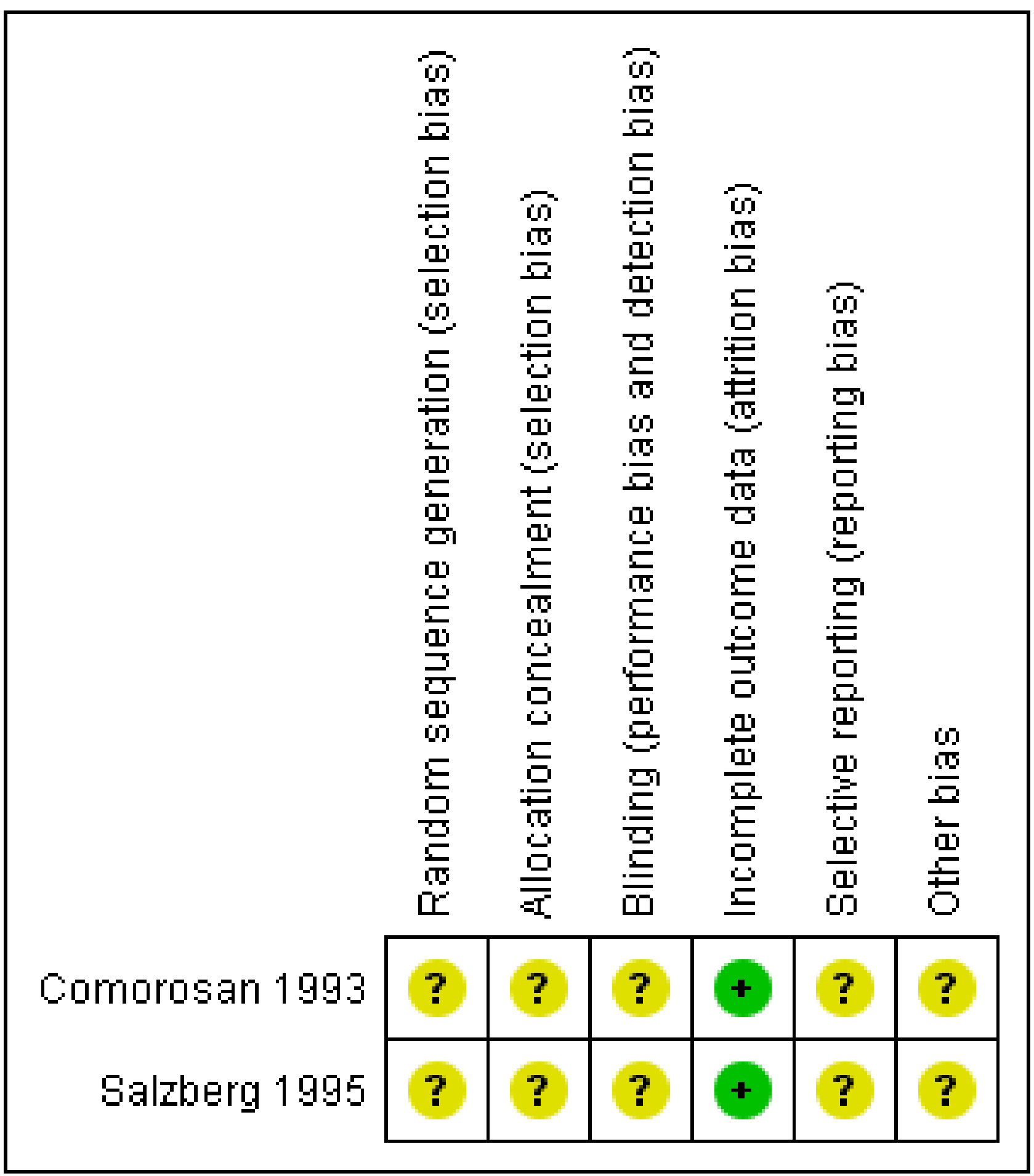

\section{Allocation}

Both trials have unclear risk of bias for sequence generation and allocation concealment. They described the allocation to treatment groups as randomised but there was no description on how randomisation was achieved. The lack of description of the allocation process also meant that the degree of allocation concealment was unclear.

\section{Blinding}

In judging the risk of bias for this item, we considered how subjective or objective an outcome is. There are particular risks of bias with more subjective outcomes (Higgins 2011). The two trials were judged to have unclear risk of bias for blinding. Both described how patients and investigators were blinded to EMT and sham EMT therapy but did not provide information on the blinding

Electromagnetic therapy for treating pressure ulcers (Review)

Copyright $\odot 2015$ The Cochrane Collaboration. Published by John Wiley \& Sons, Ltd. 
of the outcome assessors. In wound trials assessment of treatment outcome, namely reduction in surface area, involves an element of subjectivity (for example in judging where the wound edge lies), therefore it is important that outcome assessors are blinded.

\section{Incomplete outcome data}

In judging the risk of bias for this item, we considered whether missing data were imputed appropriately and whether an intention-to-treat analysis was reported for the primary outcome. The two trials were considered to have low risk of bias for incomplete outcome data. There was no loss to follow up in Comorosan 1993 while in Salzberg 1995 the loss to follow up occurred after the main outcome was assessed (after one week).

\section{Selective reporting}

In considering the risk of bias for selective reporting, we based our assessment on comparing outcomes listed in the methods section of the paper with those outcomes reported in the results section. Both trials had unclear risk of bias for selective reporting. Outcomes to be assessed were not listed in the methods section in Comorosan 1993, thus it was not clear whether the trial included all planned outcomes. In Salzberg 1995 a subset of patients with stage II pressure ulcers less than or equal to $60 \mathrm{~cm}^{2}$ and ulcer size more than $60 \mathrm{~cm}^{2}$ were analysed separately. Stage II and stage III patients were also analysed separately. These analyses were not prespecified in the methods section of the paper but may have been planned.

\section{Other potential sources of bias}

Baseline ulcer area was not reported in Comorosan 1993. Salzberg 1995 reported there was no statistically significant difference for the baseline parameters between the EMT group and the sham group for those with Stage II pressure ulcers (total $n=20$ ). However, the randomisation process did not provide for an even distribution of large pressure ulcers between the two groups with the sham EMT group having larger ulcers than the EMT group. No baseline data were provided for patients with Stage III pressure ulcers, therefore we were unable to judge whether theses two groups $(n=10)$ were comparable at the start of the study.

\section{Effects of interventions}

\section{Proportions of ulcers healed}

Two trials compared EMT with sham EMT, although the trial by Comorosan 1993 included a third arm in which only standard therapy was applied.

In the Comorosan 1993 trial, 17 out of 20 (85\%) ulcers in the EMT group achieved complete healing within the duration of treatment compared with no ulcers healing in either of the other two groups (five ulcers in each); the risk ratio (RR) was 10.00 (95\% Cl 0.70 to 143.06) (Analysis 1.1; Analysis 2.1). The difference between the groups was statistically not significant.

In the Salzberg 1995 trial, at one week three out of 10 (30\%) Stage II pressure ulcers and three out of five (60\%) Stage III pressure ulcers in the EMT group had healed, compared with none in the sham EMT group (RR $7.00,95 \% \mathrm{Cl} 0.41$ to 120.16 ) and (RR $7.0,95 \% \mathrm{Cl} 0.45$ to 108.26) respectively (Analysis 3.1). The pooled RR for Stage II and III was 7.00 (95\% Cl 0.97 to 50.38 ) (Analysis 3.1).
The results from these two studies do not indicate a statistically significant treatment effect associated with EMT in healing pressure ulcers, however there is a great deal of uncertainty as there are only two small studies, both at unclear risk of bias.

We did not combine the results of the two studies (Comorosan 1993; Salzberg 1995) because of the different treatment durations.

\section{Change in ulcer area}

Change in ulcer area was not assessed in Comorosan 1993.

In Salzberg 1995, the overall change in ulcer area was presented in the discussion section of the paper. The ulcer area reduction at one week was $77 \%(S D=21 \%)$ in the EMT group and $40 \%(S D=28 \%)$ in the sham EMT group. The mean percent difference in area reduction between the two groups was statistically significantly greater in the EMT group (RR 37\%, 95\% Cl 17.36 to 56.64) (Analysis 4.1). However, this result should be interpreted with caution for two reasons; firstly, this is a small study and there is a possibility that this finding may be due to chance differences in prognostic variables. The randomisation process did not provide for an even distribution of large pressure ulcers between the two groups with the sham EMT group having larger ulcers than the EMT group. In general, a change in area or volume would give a larger percentage reduction for a smaller ulcer than for a bigger ulcer. Subsequently, this would favour the EMT group as it has the smallest median wound size at baseline for stage II ulcers (baseline values for stage III ulcers were not provided). Secondly, the risk of bias due to generation of allocation sequence, allocation concealment and blinding of the outcome assessor was assessed as 'unclear' due to poor reporting.

\section{Time to complete healing}

Time to complete healing was reported only for the EMT group in one study (Comorosan 1993). Healing in Stage II ulcers was achieved between one and four weeks (mean 3.28 weeks), while for Stage III ulcers healing time was between two and eight weeks (mean $=4.87$ ). In Salzberg 1995, the median time to complete healing was 13 days for the EMT group, compared with 31.5 days for the sham EMT group (P value $<0.001$ ). However, the results of these two studies could not be combined as measures of variance were not reported. Furthermore baseline imbalances for wound area in Salzberg 1995 introduce bias for this outcome.

\section{Secondary outcomes}

Secondary outcomes, namely costs, quality of life, pain and acceptability of treatment were not assessed in either trial.

\section{Adverse effects}

No adverse effects were observed in Comorosan 1993, while Salzberg 1995 did not provide information on adverse effects.

\section{ISCUSSION}

There is no strong evidence from two small trials that EMT speeds pressure ulcer healing. Both trials contained small numbers of patients and used different regimens of treatment over different time scales. There was evidence from one trial showing that the EMT group achieved more reduction in wound area than the sham EMT group. However, this result needs to be interpreted with caution. The result was based on data from a trial with a moderate 
risk of bias in which randomisation sequence, concealment allocation and blinding of outcome assessor were unclear.

The extent to which EMT contributes to healing in patients who are also receiving pressure relief and moist wound healing strategies should be explored. The included trials, particularly Comorosan 1993, did not report severity of pressure ulcers and baseline comparisons adequately. Consequently, the results should be viewed as unreliable until further research involving larger numbers of patients that can be considered alongside these trials becomes available.

\section{AUTHORS' CONCLUSIONS}

\section{Implications for practice}

There is no reliable evidence of benefit for EMT in the treatment of pressure ulcers. The small number of trials available for analysis (both with methodological limitations and small numbers of participants) means that the possibility of benefit, or harm, of this treatment cannot be ruled out.

\section{Implications for research}

Trials comparing EMT with sham therapy, or standard care, are required to establish whether or not EMT improves the healing of pressure ulcers. In addition, future trials should explore whether particular subgroups of participants are more likely than others to benefit from treatment with EMT and, if the treatment is shown to be effective, to establish the point in a treatment regimen at which it should be applied.

Both studies summarised in this review were small and had methodological problems. Future trials will require:

1. participant numbers that ensure sufficient statistical power to detect true treatment effects;

2. use of true randomisation with allocation concealment (e.g. telephone randomisation, computer-generated codes);
3. measures to help ensure comparability of treatments at baseline (e.g. stratification for ulcer size);

4. blinded outcome assessment;

5. use of objective outcome measurement (e.g. ulcer area, complete healing rates); and

6. use of intention-to-treat analysis.

It is also recommended that studies should clearly describe the frequency and duration of treatment, location of wounds and any treatment(s) applied concurrently with the EMT.

Randomised controlled trials should be adequately reported. The CONSORT 2010 statement (Schulz 2010) lists 25 items that need to be reported to show readers whether or not a trial is likely to produce valid and reliable results. Further research into the relationship of EMT and pressure ulcer healing needs to be reported in accordance with these guidelines.

\section{ACK N OWLEDGEMENTS}

The authors would like to thank Ali Baba Akbari Sari and Ruth Foxlee from the Cochrane Wounds Group for their comments on the development and update of the search strategy. The authors would also like to thank Sally Bell-Syer and Wendy Milborrow from the Cochrane Wounds Group for their support and assistance during the updating process. Hamid Ravaghi worked on the first and second update of the review but is no longer involved in the updating process for this review, his contribution was to independently check the search results for new studies and he provided comment on the first update of the review. Nicky Cullum was involved as an author in the planning and writing of the original review and all updates up to 2012. Alireza Olyaee Manesh worked on the first and second update of the review but is no longer involved in the updating process for this review. Kate Fleming conducted the original review but is no longer involved in the updating process. Jenny Bellorini copy edited the third update. 


\section{RE F E R E N C E S}

\section{References to studies included in this review}

Comorosan 1993 \{published data only\}

Comorosan S, Vasilco R, Arghiropol M, Paslaru L, Jieanu V, Stelea S. The effect of Diapulse therapy on the healing of decubitus ulcer. Romanian Journal of Physiology 1993;30(1-2):41-5.

\section{Salzberg 1995 \{published data only\}}

Salzberg CA, Cooper-Vastola SA, Perez F, Viehbeck MG, Byrne DW. The effects of non-thermal pulsed electromagnetic energy on wound healing of pressure ulcers in spinal cordinjured patients: a randomized, double-blind study. Ostomy Wound Management 1995;41:42-4, 46, 48.

\section{References to studies excluded from this review}

Cooper-Vastola 1983 \{published data only\}

Cooper-Vastola SA, Salzberg CA, Viehbeck MG, Perez FJ. A randomized, double-blind study on the effects of Diapulse on wound healing in pressure ulcers. Journal of American Paraplegia Society 1983;16(4):263-4.

Goldin 1981 \{published data only\}

Goldin JH, Broadbent NRG, Nancarrow JD, Marshall T. The effects of Diapulse on the healing of wounds: a double-blind randomised controlled trial in man. British Journal of Plastic Surgery 1981;34(3):267-70.

\section{Gupta 2009 \{published data only\}}

Gupta A, Taly AB, Srivastava A, Kumar S, Thyloth M. Efficacy of pulsed electromagnetic field therapy in healing of pressure ulcers: a randomized control trial. Neurology India 2009;57(5):622-6.

\section{Itoh 1991 \{published data only\}}

Itoh M, Montemayor JS Jr, Matsumoto E, Eason A, Lee MH, Folk FS. Accelerated wound healing of pressure ulcers by pulsed high peak power electromagnetic energy (Diapulse). Decubitus 1991;4(1):24-5, 29-34.

\section{Seaborne 1996 \{published data only\}}

Seaborne D, Quirion-DeGirardi C, Rousseau M, Rivest M, Lambert J. The treatment of pressure sores using pulsed electromagnetic energy (PEME). Physiotherapy Canada 1996;48(2):131-7.

\section{Ullah 2007 \{published data only\}}

Ullah MO. A study to detect the efficacy of Micro-current Electrical Therapy on decubitus wound. Journal of Medical Sciences 2007;7(8):1320-4.

\section{Additional references}

\section{Athanasiou 2007}

Athanasiou A, Karkambounas S, Batistatou A, Lykoudis E, Katsaraki A, Kartsiouni T, et al. The effect of pulsed electromagnetic fields on secondary skin wound healing: an experimental study. Bioelectromagnetics 2007;28(5):362-8.

\section{Bennett 2004}

Bennett G, Dealey C, Posnett J. The cost of pressure ulcers in the UK. Age and Ageing 2004;33(3):230-5.

\section{Clark 1994}

Clark M. The financial cost of pressure ulcer in the UK National Health Services. Proceedings of 4th European Conference on Avdances in Wound Management. London: Macmillan, 1994:48-51.

\section{EPUAP 2002}

EPUAP 2002 European Pressure Ulcer Advisory Panel. Summary report on the prevalence of pressure ulcers. EPUAP Review 2002;4(2):49-57.

\section{EPUAP-NPUAP 2009}

European Pressure Ulcer Advisory Panel and National Pressure Ulcer Advisory Panel. Treatment of pressure ulcers: Quick Reference Guide. Washington DC: National Pressure Ulcer Advisory Panel, 2009.

\section{Gordon 2007}

Gordon GA. Designed electromagnetic pulsed therapy: clinical applications. Journal of Cellular Physiology 2007;212(3):579-82.

\section{Haddad 2007}

Haddad JB, Obolensky AG, Shinnick P. The biologic effects and the therapeutic mechanism of action of electric and electromagnetic field stimulation on bone and cartilage: new findings and a review of earlier work. Journal of Alternative and Complementary Medicine 2007;13(5):485-90.

\section{Higgins 2011}

Higgins JPT and Altman DG on behalf of the Cochrane Statistical Methods Group and the Cochrane Bias Methods Group (Editors). Chapter 8: Assessing risk of bias in included studies. In: Higgins JPT, Green S (editors). Cochrane Handbook for Systematic Reviews of Interventions Version 5.1.0 [updated March 2011]. The Cochrane Collaboration, 2011. Available from www.cochrane-handbook.org.

\section{Kaltenthaler 2001}

Kaltenthaler E, Whitfield MD, Walters SJ, Akehurst RL, Paisley S. UK, USA and Canada: how do their pressure ulcer prevalence and incidence compare?. Journal of Wound Care 2001;10(1):530-5.

\section{Kenkre 1996}

Kenkre JE, Hobbs FD, Carter YH, Holder RL, Holmes EP. A randomized controlled trial of electromagnetic therapy in the primary care management of venous leg ulceration. Family Practice 1996;13(3):236-41.

\section{Kitchen 2002}

Kitchen S. Electrotherapy: Evidence-Based Practice. Eleventh. Edinburgh: New York: Churchill-Livingstone, 2002. 


\section{Lee 1993}

Lee RC, Canaday DJ, Doong H. A review of the biophysical basis for the clinical application of electric fields in soft-tissue repair. Journal of Burn Care and Rehabilitation 1993;14(3):319-35.

\section{Lefebvre 2011}

Lefebvre C, Manheimer E, Glanville J, on behalf of the Cochrane Information Retrieval Methods Group. Chapter 6: Searching for studies. In: Higgins JPT, Green S (editors). Cochrane Handbook for Systematic Reviews of Interventions Version 5.1.0 [updated March 2011]. The Cochrane Collaboration, 2011. Available from www.cochrane-handbook.org.

\section{Markoll 2003}

Markoll R, Da Silva Ferreira DM, Toohil TK. Pulsed Signal Therapy ${ }^{\circledR}$ : An overview. APLAR Journal of Rheumatology 2003;6(1):89-100.

\section{Markov 2007}

Markov MS. Expanding use of pulsed electromagnetic field therapies. Electromagnetic Biology and Medicine 2007;26(3):257-74

\section{McGaughey 2009}

McGaughey H, Dhamija S, Oliver S, Porter-Armstrong A, McDonough S. Pulsed electromagnetic energy in management of chronic wounds: a systematic review. Physical Therapy Reviews 2009;14(2):132-46.

\section{Ryaby 1998}

Ryaby JT. Clinical effects of electromagnetic and electric fields on fracture healing. Clinical Orthopaedics and Related Research 1998;355(Suppl):S205-15.

\section{CHARACTERISTICS OF STUDIES}

Characteristics of included studies [ordered by study ID]

\section{Schulz 2010}

Schulz KF, Altman DG, Moher D, for the CONSORT Group. CONSORT 2010 Statement: updated guidelines for reporting parallel group randomised trials. BMJ 2010;340 Mar 23:c332.

\section{Shupak 2006}

Shupak NM, McKay JC, Nielson WR, Rollman GB, Prato FS, Thomas AW. Exposure to a specific pulsed low-frequency magnetic field: a double-blind placebo-controlled study of effects on pain ratings in rheumatoid arthritis and fibromyalgia patients. Pain Research and Management 2006;11(2):85-90.

\section{SIGN 2010}

Scottish Intercollegiate Guidelines Network (SIGN). Search filters. http://www.sign.ac.uk/methodology/ filters.html\#random (accessed 2 June 2010).

\section{Stiller 1992}

Stiller MJ, Pak GH, Shupack JL, Thaler S, Kenny C, Jondreau L. A portable pulsed electromagnetic field (PEMF) device to enhance healing of recalcitrant venous ulcers: a double-blind, placebo-controlled clinical trial. British Journal of Dermatology 1992;127(2):147-54.

\section{Thomas 2007}

Thomas AW, Graham K, Prato FS, McKay J, Forster PM, Moulin DE, et al. A randomized, double-blind, placebocontrolled clinical trial using a low-frequency magnetic field in the treatment of musculoskeletal chronic pain. Pain Research and Management 2007;12(4):249-58.

\section{Touche Ross 1993}

Touche Ross, Company. The costs of pressure sores. Report to the Department of Health, UK 1993.

\section{Comorosan 1993}

\begin{tabular}{ll}
\hline Methods & RCT \\
\hline Participants & 30 (13 M;17 F) patients in an elderly care unit with either Stage II (16 participants) or Stage III (14 partic- \\
ipants) pressure ulcer. Ulcers were located on the buttocks (9), sacrum (8), knee (6), coxal (2), back (3), \\
heel(1) and leg (1). \\
Ulcer stages not defined. No report on patients' mobility status.
\end{tabular}

Interventions

Group 1: $(n=20)$ Diapulse $^{\circledR}$ plus conventional therapy*

Local application at a frequency of $600 \mathrm{pps}$, peak power $6(117 \mathrm{~V}, 27.12 \mathrm{MHz})$, for 30 minutes $2 \mathrm{x}$ daily. Hepatic application - 400 pps, peak power 4 (117 V, $27.12 \mathrm{MHz}), 20$ minutes $1 \mathrm{x}$ daily, following initial Diapulse ${ }^{\circledR}$ treatment.

Group 2: $(n=5)$ sham Diapulse ${ }^{\circledR}$ plus conventional therapy ${ }^{\star}$ Group 3: $(n=5)$ conventional therapy ${ }^{\star}$

${ }^{*}$ Conventional therapy consisted of $\mathrm{H}_{2} \mathrm{O}_{2}$ cleansing and local applications of talcum powder, methylene blue in solution and tetracycline ointments

Outcomes The outcomes assessed were proportion of ulcers healed and time to complete healing

PRIMARY OUTCOMES: 
Comorosan 1993 (Continued)

a) Number of ulcers healed at 5 weeks:

Group 1: 16/20

Group 2: 0/5

Group 3: 0/5

b) Rate of change in ulcer area: Not assessed in this study

c) Time to complete healing (weeks):

Stage II ulcers - achieved in ( 1 to 4 ); mean $=3.28$ (no variance data reported)

Stage III ulcers - achieved in ( 2 to 8 ); mean $=4.87$ (no variance data reported)

\section{SECONDARY OUTCOMES:}

d) Adverse effects: Reported no adverse effects

The trial had no loss to follow up Locations of wounds were provided.

\section{Risk of bias}

\begin{tabular}{|c|c|c|}
\hline Bias & Authors' judgement & Support for judgement \\
\hline $\begin{array}{l}\text { Random sequence genera- } \\
\text { tion (selection bias) }\end{array}$ & Unclear risk & $\begin{array}{l}\text { Comment: allocation to the } 3 \text { treatment groups was described as "randomly } \\
\text { organized" but there was no description of how randomisation was achieved. }\end{array}$ \\
\hline $\begin{array}{l}\text { Allocation concealment } \\
\text { (selection bias) }\end{array}$ & Unclear risk & Comment: no description of the process of allocation. \\
\hline $\begin{array}{l}\text { Blinding (performance } \\
\text { bias and detection bias) } \\
\text { All outcomes }\end{array}$ & Unclear risk & $\begin{array}{l}\text { Comment: whilst "technician in charge, nor the clinician" were reportedly } \\
\text { blinded to Diapulse }{ }^{\circledR} \text { and sham therapy, it would not have been possible to } \\
\text { blind the third group. There was also no information on whether the outcome } \\
\text { assessor was blinded. }\end{array}$ \\
\hline $\begin{array}{l}\text { Incomplete outcome data } \\
\text { (attrition bias) } \\
\text { All outcomes }\end{array}$ & Low risk & Comment: reported no loss to follow up. \\
\hline $\begin{array}{l}\text { Selective reporting (re- } \\
\text { porting bias) }\end{array}$ & Unclear risk & $\begin{array}{l}\text { Comment: outcomes to be assessed were not stated in the methods section } \\
\text { of the article, therefore it was not clear whether the trial included all planned } \\
\text { outcomes. No access to trial protocol. }\end{array}$ \\
\hline Other bias & Unclear risk & $\begin{array}{l}\text { The median baseline ulcer area varied between the } 3 \text { groups. This difference } \\
\text { may bias the evaluation in favour of the Diapulse }{ }^{\circledR} \text { group as this group has the } \\
\text { lowest value (ulcer size). }\end{array}$ \\
\hline
\end{tabular}

Salzberg 1995

\begin{tabular}{|c|c|}
\hline Methods & $\mathrm{RCT}$ \\
\hline Participants & $\begin{array}{l}30(30 \mathrm{M}) \text { inpatients with spinal cord compression and a Stage II }(n=20) \text { or Stage III }(n=10) \text { pressure ul- } \\
\text { cer. Grading defined by authors. Patients in both stage II and III were allocated in equal numbers to the } \\
\text { control and intervention groups. }\end{array}$ \\
\hline & $\begin{array}{l}\text { Baseline features: Reported - duration of ulcers prior to admission, degree of edema, erythema, epithe- } \\
\text { lialization, and ulcer size. Satge II patients there was no statistically significant difference for the base- } \\
\text { line parameters between the } 10 \text { in the EMT group and the } 10 \text { in the sham group. But the randomisa- }\end{array}$ \\
\hline
\end{tabular}


Salzberg 1995 (Continued)

tion process did not provide for an even distribution of large pressure ulcers. No data were reported on baseline parameters from the 10 patients with Satge II pressure ulcers.

Interventions

Group 1: $(n=15)$ electromagnetic energy at a frequency of $27.12 \mathrm{MHz}$, pulse repetition 80 to $600 \mathrm{pps}$, pulse width 65 microseconds, per pulse power range of 293 and 975 peak watts - delivered through wound dressing, 30 minutes treatment $2 x$ daily for 12 weeks.

Group 2: $(n=15)$ sham treatment as above.

All ulcers were dressed with moist saline gauze.

Outcomes The outcomes assessed were proportion of ulcers healed, percent of ulcers healed (defined as reduction in wound surface area from the initial measurements) and time to complete healing.

\section{PRIMARY OUTCOMES:}

a) Number of ulcers healed within 1 week:

Stage II ulcer: Group $1=3 / 10 ;$ Group $2=0 / 10$

Stage III ulcer: Group $1=3 / 5$; Group $2=0 / 5$

b) Percent reduction in ulcers surface area at 1 week:

Stage II ulcer (median): Group $1=84$; Group $2=40$

Stage III ulcer (mean): Group 2 = 70.6; Group 2 $=20.7$

Percent overall reduction (SD): (this result was presented in the discussion section of the paper)

Group 1: 77 (21)

Group 2: 40 (28)

c) Time to complete healing in days (median):

Stage II ulcers: Group $1=13$; Group $2=31.5(P<0.001)$

Stage III ulcers: not reported

\section{SECONDARY OUTCOMES:}

d) Adverse effects: No adverse effects reported

e) Cost: Suggested it would be more cost effective but did not provide data

The trial has 1 loss to follow up in the EMT group after week 1

Notes No report of concurrent pressure relief used, such as support surfaces (bed, mattresses and cushions)

\section{Risk of bias}

\begin{tabular}{lll}
\hline Bias & Authors' judgement & Support for judgement \\
\hline $\begin{array}{l}\text { Random sequence genera- } \\
\text { tion (selection bias) }\end{array}$ & Unclear risk & $\begin{array}{l}\text { Comment: allocation to the treatment groups was described as "randomly as- } \\
\text { signed to receive therapy from either an active or control sham" but there was } \\
\text { no description of how randomisation was achieved }\end{array}$ \\
\hline
\end{tabular}

Allocation concealment Unclear risk $\quad$ Comment: no description of the process of allocation
(selection bias)

Blinding (performance Unclear risk

bias and detection bias)

All outcomes
Comment: "Patients, staff and authors were blinded to the identity of the functioning unit" and the sham unit was identical in operation, appearance, and sound to the active unit, the study described that the outcomes were assessed by a single observer. It was unclear if this assessor was blinded.

Incomplete outcome data Low risk $\quad \begin{aligned} & \text { Comment: the trial had one loss to follow up after the outcome was assessed, } \\ & \text { (attrition bias) }\end{aligned}$
week 1 (the outcomes were reported at week 1)
All outcomes

Comment: the trial had one loss to follow up after the outcome was assessed,

Selective reporting (re- Unclear risk
porting bias)

Comment: subset of patients with Stage II pressure ulcers less than or equal to porting bias) 


\begin{tabular}{|c|c|c|}
\hline Other bias & Unclear risk & $\begin{array}{l}\text { Comment: baseline data were provided only for patients with Stage II but not } \\
\text { for patients with Stage III pressure ulcers }\end{array}$ \\
\hline
\end{tabular}

Abbreviations:

$\mathrm{H}_{2} \mathrm{O}_{2}=$ hydrogen peroxide

$\mathrm{n}=$ number in sample group

pps $=$ pulses per second

$\mathrm{x}=$ times

Characteristics of excluded studies [ordered by study ID]

\begin{tabular}{ll}
\hline Study & Reason for exclusion \\
\hline Cooper-Vastola 1983 & $\begin{array}{l}\text { In the initial assessment, the title of article seemed relevant to the objective of the review. The ab- } \\
\text { stract of the study was unavailable. We requested the article via an interlibrary loan and direct con- } \\
\text { tact with the author and the journal publisher (Journal of American Paraplegia Society), all of which } \\
\text { were unsuccessful. Therefore, this study was excluded for pragmatic reasons because its content } \\
\text { could not be verified firsthand. }\end{array}$ \\
\hline
\end{tabular}

Goldin $1981 \quad$ This study assessed wound healing of the donor site

\begin{tabular}{ll}
\hline Gupta 2009 & Bates-Jensen wound assessment tool (also known as Pressure Sore Status Tool) was used to as- \\
sess the main outcome measure. Data to validate the use of this tool to assess wound healing are \\
still limited.
\end{tabular}

\begin{tabular}{ll}
\hline Itoh 1991 & Not a controlled trial \\
\hline Seaborne 1996 & $\begin{array}{l}\text { Not a controlled trial. This study did not meet the inclusion criteria as it evaluated the effectiveness } \\
\text { of pulsed electromagnetic energy in the treatment of pressure ulcers using } 4 \text { different protocols } \\
\text { (treatment plans). }\end{array}$ \\
\hline Ullah 2007 & $\begin{array}{l}\text { This study did not meet the inclusion criteria as it examined micro current stimulation therapy and } \\
\text { not electromagnetic therapy }\end{array}$ \\
\hline
\end{tabular}

\section{DATA AND ANALYSES}

\section{Comparison 1. Electromagnetic therapy versus sham electromagnetic therapy}

\begin{tabular}{lllll}
\hline Outcome or subgroup title & No. of studies & $\begin{array}{l}\text { No. of partici- } \\
\text { pants }\end{array}$ & Statistical method & Effect size \\
\hline $\begin{array}{l}1 \text { Pressure ulcers healed within 8 weeks } \\
\text { of treatment }\end{array}$ & 1 & & $\begin{array}{l}\text { Risk Ratio (M-H, Fixed, 95\% } \\
\text { Cl) }\end{array}$ & Subtotals only \\
\hline
\end{tabular}


Analysis 1.1. Comparison 1 Electromagnetic therapy versus sham electromagnetic therapy, Outcome 1 Pressure ulcers healed within 8 weeks of treatment.

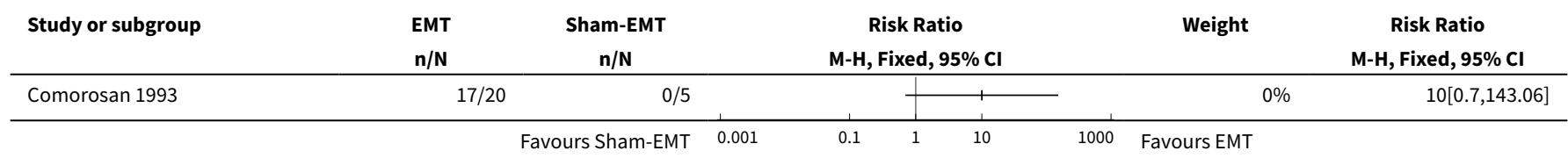

\section{Comparison 2. Electromagnetic therapy versus standard therapy alone}

\begin{tabular}{lllll}
\hline Outcome or subgroup title & No. of studies & $\begin{array}{l}\text { No. of partici- } \\
\text { pants }\end{array}$ & Statistical method & Effect size \\
\hline $\begin{array}{l}1 \text { Pressure ulcers healed within 8 weeks } \\
\text { of treatment duration }\end{array}$ & 1 & & $\begin{array}{l}\text { Risk Ratio (M-H, Random, } \\
95 \% \mathrm{Cl})\end{array}$ & Subtotals only \\
\hline
\end{tabular}

Analysis 2.1. Comparison 2 Electromagnetic therapy versus standard therapy alone, Outcome 1 Pressure ulcers healed within 8 weeks of treatment duration.

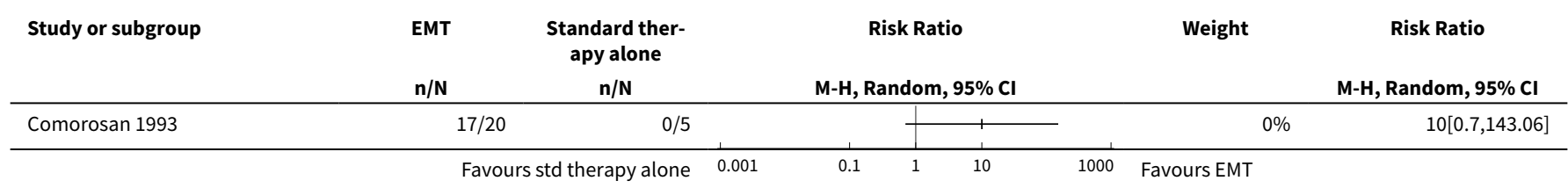

Comparison 3. Electromagnetic therapy versus sham electromagnetic therapy

\begin{tabular}{llllll}
\hline Outcome or subgroup title & No. of studies & $\begin{array}{l}\text { No. of partici- } \\
\text { pants }\end{array}$ & Statistical method & Effect size \\
\hline 1 Healed ulcers at one week & 1 & 30 & Risk Ratio (M-H, Fixed, 95\% Cl) & $7.0[0.97,50.38]$ \\
\hline 1.1 Stage II ulcers & 1 & 20 & Risk Ratio (M-H, Fixed, 95\% Cl) & $7.0[0.41,120.16]$ \\
\hline 1.2 Stage III ulcers & 1 & 10 & Risk Ratio (M-H, Fixed, 95\% Cl) & $7.0[0.45,108.26]$ \\
\hline
\end{tabular}

Analysis 3.1. Comparison 3 Electromagnetic therapy versus sham electromagnetic therapy, Outcome 1 Healed ulcers at one week.

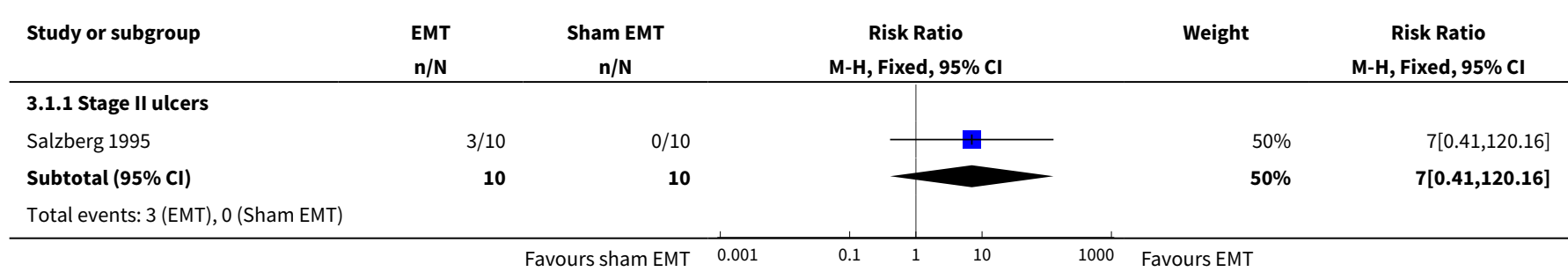




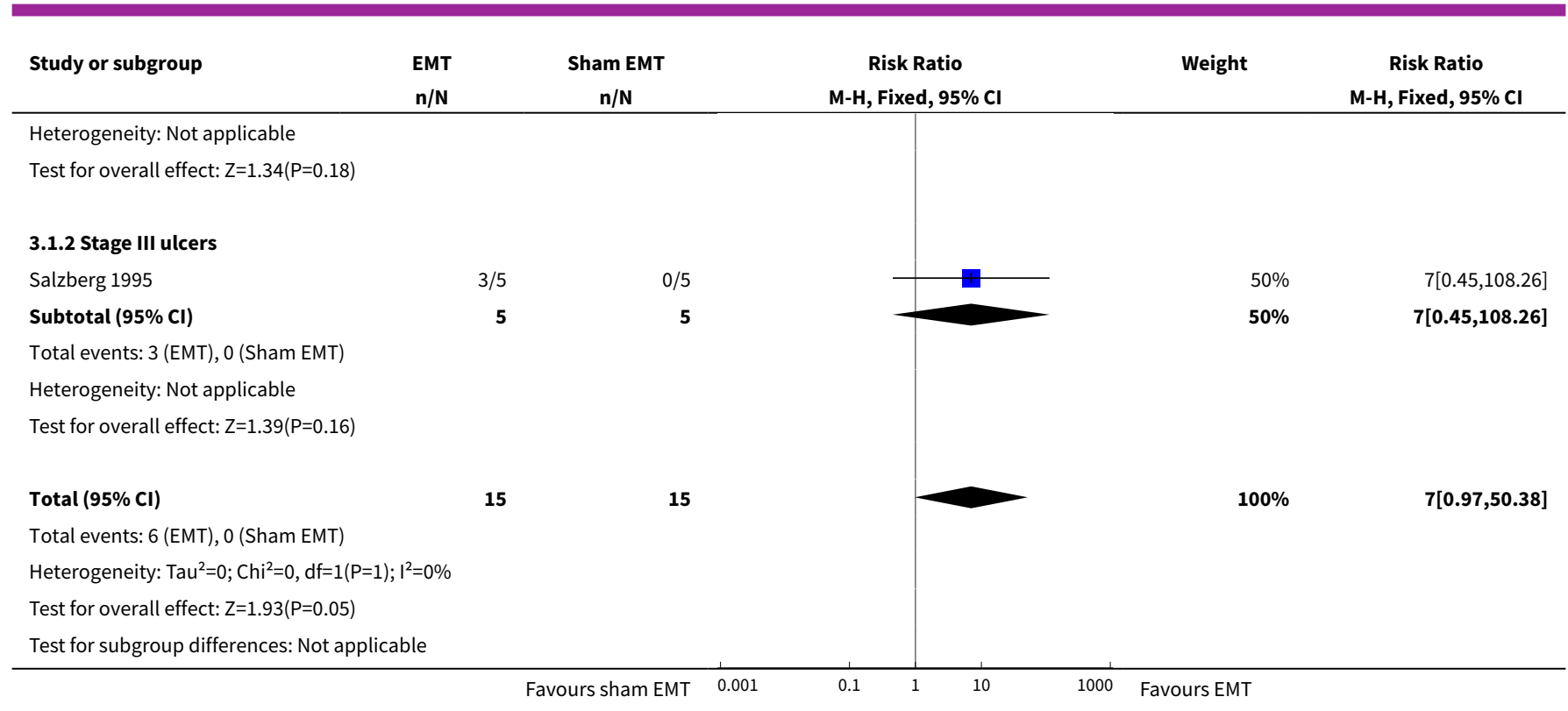

\section{Comparison 4. Electromagnetic therapy versus sham electromagnetic therapy}

\begin{tabular}{lllll}
\hline Outcome or subgroup title & No. of studies & $\begin{array}{l}\text { No. of partici- } \\
\text { pants }\end{array}$ & Statistical method & Effect size \\
\hline $\begin{array}{l}1 \text { Percent reduction in wound surface } \\
\text { area at one week }\end{array}$ & 1 & 30 & $\begin{array}{l}\text { Mean Difference (IV, Fixed, } \\
95 \% \mathrm{Cl})\end{array}$ & $\begin{array}{l}37.0[17.36, \\
56.64]\end{array}$ \\
\hline
\end{tabular}

Analysis 4.1. Comparison 4 Electromagnetic therapy versus sham electromagnetic therapy, Outcome 1 Percent reduction in wound surface area at one week.

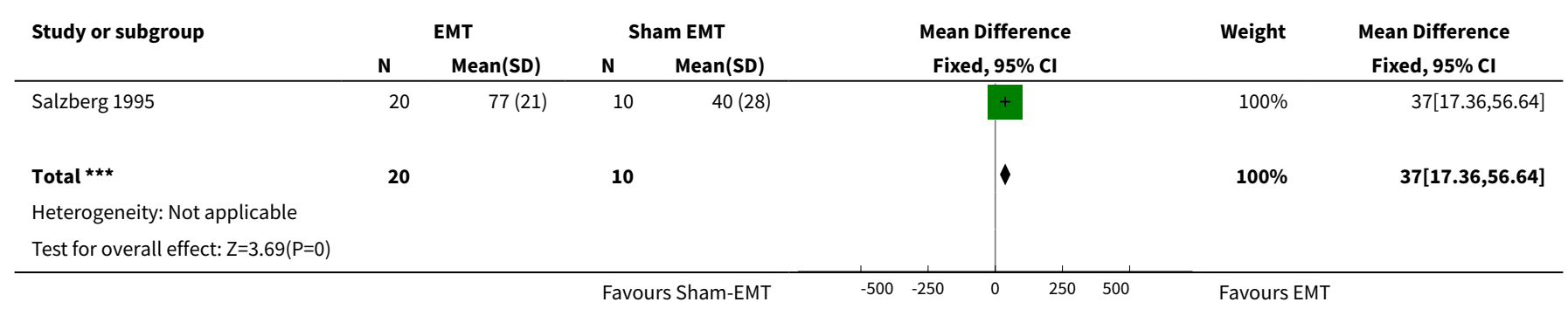

\section{AP PE N D I C E S}

\section{Appendix 1. Search strategy - fourth update 2012}

\section{Electronic searches}

For this fourth update of the review, we revised the search strategies and ran searches in the following databases to find randomised controlled trials (RCTs) of EMT:

- The Cochrane Wounds Group Specialised Register (searched 30 September 2012); 
- The Cochrane Central Register of Controlled Trials (CENTRAL) (The Cochrane Library 2012, Issue 8);

- Ovid MEDLINE (2010 to July Week 12012 );

- Ovid MEDLINE (In-Process \& Other Non-Indexed Citations, July 11, 2012);

- Ovid EMBASE (2010 to 2012 Week 27);

- EBSCO CINAHL (2010 to 6 July 2012)

The search strategies for Ovid MEDLINE, Ovid EMBASE and EBSCO CINAHL can be found in Appendix 2; Appendix 3 and Appendix 4 respectively. The Ovid MEDLINE search was combined with the Cochrane Highly Sensitive Search Strategy for identifying randomised trials in MEDLINE: sensitivity- and precision-maximizing version (2008 revision); Ovid format. The EMBASE and CINAHL searches were combined with the trial filters developed by the Scottish Intercollegiate Guidelines Network. There were no restrictions on the basis of language or date of publication.

\section{Searching other resources}

For the original review and the first update, experts in the field (e.g. SA Cooper-Vastola) and manufacturers (Diapulse ${ }^{\circledR}$ and Elmedistraal ${ }^{\circledR}$ ) were also contacted and asked to provide any information they might have about unpublished studies. In the second update we checked the reference list of the systematic review by McGaughey 2009 for additional studies.

\section{Appendix 2. Ovid MEDLINE search strategy}

1 exp Electromagnetics/

2 exp Electric Stimulation Therapy/

3 (electromagnetic\$ or electrotherap\$).ti,ab.

4 (electric\$ adj stimulation).ti,ab.

5 (electric $\$$ adj current).ti,ab.

6 ((direct or pulsed or alternating) adj current).ti,ab.

7 (low intensity or low frequency).ti,ab.

8 high voltage.ti,ab.

9 (TENS or NMES).ti,ab.

10 interferential therap\$.ti,ab.

11 (monophasic or galvanic).ti,ab.

12 exp Diathermy/

13 exp Microwaves/

14 (diathermy or microwave\$).ti,ab.

15 or/1-14

16 exp Pressure Ulcer/

17 (pressure adj (ulcer\$ or sore\$)).ti,ab.

18 (decubitus adj (ulcer\$ or sore\$)).ti,ab.

19 (bedsore\$ or (bed adj sore\$)).ti,ab.

20 or/16-19

$21 \quad 15$ and 20

\section{Appendix 3. Ovid EMBASE search strategy}

1 exp Electromagnetic Field/

2 exp Electrostimulation Therapy/

3 (electromagnetic $\$$ or electrotherap\$).ti,ab.

4 (electric $\$$ adj stimulation).ti,ab.

5 (electric $\$$ adj current).ti,ab.

6 ((direct or pulsed or alternating) adj current).ti,ab.

7 (low intensity or low frequency).ti,ab.

8 high voltage.ti,ab.

9 (TENS or NMES).ti,ab.

10 interferential therap\$.ti,ab.

11 (monophasic or galvanic).ti,ab.

12 exp Diathermy/

13 exp Microwaves/

14 (diathermy or microwave\$).ti,ab.

15 or/1-14

16 exp Decubitus/

17 (pressure adj (ulcer\$ or sore\$)).ti,ab.

18 (decubitus adj (ulcer\$ or sore\$)).ti,ab.

19 (bedsore\$ or (bed adj sore\$)).ti,ab. 
20 or/16-19

2115 and 20

\section{Appendix 4. EBSCO CINAHL search strategy}

S21 S15 and S20

$\mathrm{S} 20 \mathrm{~S} 16$ or $\mathrm{S} 17$ or $\mathrm{S} 18$ or $\mathrm{S} 19$

S19 TI decubitus or AB decubitus

S18 TI ( bed sore* or bedsore*) or AB ( bed sore* or bedsore* )

S17 $\mathrm{TI}$ ( pressure ulcer ${ }^{\star}$ or pressure sore ${ }^{\star}$ ) or $\mathrm{AB}$ ( pressure ulcer $^{\star}$ or pressure sore ${ }^{\star}$ )

S16 (MH "Pressure Ulcer")

$\mathrm{S} 15 \mathrm{~S} 1$ or $\mathrm{S} 2$ or $\mathrm{S} 3$ or $\mathrm{S} 4$ or $\mathrm{S} 5$ or $\mathrm{S} 6$ or $\mathrm{S} 7$ or $\mathrm{S} 8$ or $\mathrm{S} 9$ or $\mathrm{S} 10$ or $\mathrm{S} 11$ or $\mathrm{S} 12$ or $\mathrm{S} 13$ or $\mathrm{S} 14$

$\mathrm{S} 14 \mathrm{TI}$ ( diatherm or microwave* ) or AB (diatherm or microwave* )

S13 (MH "Microwaves")

S12 (MH "Diathermy+")

$\mathrm{S} 11 \mathrm{TI}$ ( monophasic or galvanic) or AB (monophasic or galvanic)

S10 Tl interferential therap* or AB interferential therap*

S9 TI ( TENS or NMES) or AB ( TENS or NMES)

$S 8 \mathrm{TI}$ high voltage or $A B$ high voltage

$\mathrm{S} 7 \mathrm{TI}$ ( low intensity or low frequency) or $\mathrm{AB}$ ( low intensity or low frequency)

$\mathrm{S} 6 \mathrm{TI}$ ( direct current or pulsed current or alternating current) or $\mathrm{AB}$ ( direct current or pulsed current or alternating current )

S5 TI electric* current or AB electric* current

S4 TI electric* stimulation or $\mathrm{AB}$ electric ${ }^{\star}$ stimulation

S3 TI ( electromagnetic ${ }^{*}$ or electrotherap ${ }^{\star}$ ) or AB ( electromagnetic* or electrotherap*

S2 (MH "Electric Stimulation+")

S1 (MH "Electromagnetics+")

\section{FEE D B A C K}

\section{Comment from Prof Comorosan September 2002}

\section{Summary}

Your review analyzed two papers:

1. The effects of Diapulse Therapy on the healing of decubitus ulcers. Comoroson S, et al, Romanian Journal of Physiology;1993, 30, 41-5.

2. The effects of pulsed EM (Diapulse) on wound healing of pressure ulcers in the spinal cord injured patients. Salzberg CA. et al, Wounds, $1995 ; 7,1,11-16$

The reviewer's conclusions: "Neither study found a statistically significant difference between the healing rates of electromagnetic therapy treated and control group patients. The results suggest no evidence of a benefit in using electromagnetic therapy to treat pressure ulcers."

This conclusion can not be correct.

The first study (Comorosan 1993) I performed, and the results did in fact prove that Diapulse was a benefit in treating pressure ulcers. The study was performed in accordance with the main request of the statistical studies: randomized groups and double blind assessments. Moreover, it refers to a placebo group, compared to a control (conventional treatment) and an experimental one (Diapulse and Conventional). After controlling the patients' baseline, the null hypothesis is implicitly assumed: there will be no statistically significant difference in the healing rates of patients receiving Diapulse therapy and those who receive placebo treatment. Evaluation of the healing process is basically a qualitative medical assessment. Apart from size, no other quantitative (reliable) parameters are available. Granulation percentage and epithelialization percentage were used to establish the classic scale of the healing process: excellent (healed), very good ( $75-95 \%$ healed), good (50-75\% healed), fair (25-50\% healed), poor (less than $25 \%$ healed) and no improvement.

The results showed:

${ }^{*}$ In the conventional treatment group of 5 patients, 4 were rated unhealed and 1 less than $25 \%$.

${ }^{*}$ In the conventional treatment and placebo Diapulse group of 5 patients, all were rated unhealed.

${ }^{*}$ In the Diapulse treated group of 20 patients, 18 were rated healed and 2 between $75-95 \%$.

20 cases healed versus 10 unhealed, and the reviewers statement that there is not a significant difference and no evidence of benefit from the electromagnetic therapy as one can see, is completely false and misleading.

I suggest you re-read the study, and correct the assumptions that are clearly ignoring clear-cut evidence. Based on the fact that an evaluation was made after 5 weeks for the untreated Diapulse group and only 3 weeks for the Diapulse treated group, there was significant benefit for the treated group. 
In the second published study (Salzberg 1995), the authors concluded that, "Diapulse treatment significantly improved healing." Strong evidence of 30 spinal cord injured patients, treated successfully with Diapulse therapy is presented, again in a randomized doubleblind study. The baseline comparison of active Diapulse treatment versus placebo included each ulcer's area, granulation percentage and epithelialization percentage and was assessed by P-value, based on Mann-Whitney $U$ tests. The authors used chi-square statistics for categorical variables and t-test for normal distribution. For the entire group of 30 participants (20 stage II and 10 stage III), a clear acceleration of wound healing was recorded.

After controlling the size, granulation and epithelialization, Diapulse treatment was found to be independently associated with percent healed at one week $(P=.002)$ and days to $100 \%$ healing $(P=0.007)$.

Somehow these data were ignored. Average percentage healing achieved at one week was $77 \%$ in the treated group (standard deviation of $21 \%$ ) versus $40 \%$ in the control group (standard deviation of $28 \%$ ). This translates into an advantage of 3 to 1 for the active Diapulse treated group. Again, ignoring this strong evidence, it was considered devoid of statistical significance and judged to be without therapeutic merit.

\section{Reply}

Clinical decision making should give due weight to the research evidence, and that weight is determined by the volume and validity of the research. The validity of a study is the extent to which its design and conduct are likely to prevent systematic errors or bias (Moher et al, 1995). The criteria by which we assessed the validity of the primary research studies were pre-determined and peer reviewed, and are also internationally accepted as important criteria by which to judge studies which aim to evaluate the clinical effects of interventions. It is only by making rigorous, systematic assessment of the primary studies using criteria which have been determined a priori, and peer reviewed, that we can minimise biases in the review process and be sure of identifying biases in the primary research which may lead to invalid study results.

Generally, Cochrane Reviews tend to use the following broad criteria when assessing the internal validity of primary research studies (usually RCTs):

- Protection against selection bias. An unpredictable allocation sequence must be generated e.g. by computer algorithm, and then this sequence must be concealed from investigators who are enrolling patients. Knowledge of impending assignments can cause selective enrolment of patients based on prognostic factors (Schulz et al). We therefore look to the trial report, and try to contact investigators possible, to satisfy ourselves that there was true randomisation with allocation concealment. We also look for evidence that the randomisation was successful in providing treatment groups which are balanced for important prognostic variables (particularly baseline wound size in wound care studies, since wound size is known to predict time to heal).

- Protection against performance and detection bias. Performance bias occurs if any additional therapeutic interventions are provided to one of the comparison groups. Blinding of patients and care providers helps prevent this kind of bias as well as reducing the chance of differences in placebo responses between the groups. Detection bias may arise if knowledge of the patient assignment can influence the measure of outcome.

- Protection against attrition bias. Protocol deviations and loss to follow up may lead to exclusion of patients after they have been allocated to treatment groups. Such 'lost' patients are unlikely to be representative of all patients in a study as is also the case with patients who do not 'adhere' to the treatment. All patients should be analysed in the groups to which they were randomised on an 'intention-to-treat' principle, so maintaining the randomisation and avoiding selection bias.

I would like to address our assessment of the internal validity of each of the papers in this review separately.

Comorosan et al. The effect of Diapulse therapy on the healing of decubitus pressure sores. Romanian Journal of Physiotherapy $1993,30,41-5$.

Allocation to the three treatment groups in this study was described as randomised, however, we always look for a report of how this randomisation was achieved in order to satisfy ourselves that selection bias was avoided. There was no such description nor explanation of why there were 20 patients in the treatment group and five patients in each of the other therapy groups (obviously having unequal treatment groups is a potentially valid approach but the allocation must be by a random process). The lack of a description of the process of allocation also meant that we were unable to ascertain the degree of allocation concealment - which also protects against selection bias (see above). However if you can provide us with information we will happily consider it.

During our validity assessment we also look for evidence of successful randomisation demonstrated by treatment groups which are balanced at baseline for important prognostic factors such as wound size. Balanced allocation is frequently not achieved in studies as small as this. Tests for 'significant' differences are unhelpful in detecting baseline differences since a) they are underpowered, and b) any differences have by definition arisen by chance if the patients were randomised. Whilst you did not report the average baseline wound area in your paper, your recent correspondence has just prompted us to calculate it from Tables 2, 3 and 4 in your paper. The median baseline ulcer area in the conventional treatment group was $3.9 \mathrm{~cm}^{2}, 9 \mathrm{~cm}^{2}$ for the placebo treatment group, and $3.8 \mathrm{~cm}^{2}$ for the electromagnetic treatment group. This baseline difference biases the evaluation in favour of the electromagnetic treatment group. Percentage reduction in wound area is a measure that is itself biased in favour of the treatment group with the smallest average wound size at baseline (since a change in area or volume will be a larger percentage of a smaller wound than a bigger wound), whereas actual changes in size bias towards 
larger wounds. Time to complete wound healing is also a measure which would bias the study in favour of the active treatment group since smaller wounds take longer to heal. The baseline inequalities in this study were not adjusted for in the analysis.

Turning now to the possibility of performance and detection bias in this study, whilst clinicians and technicians were reportedly blinded to Diapulse and sham Diapulse therapy, it would not have been possible to blind to the third therapy. Furthermore you do not state who measured outcome (was it "the clinician"? Was there only one?). We are sure you are aware of the biases that can occur due to lack of blinding. One of our major concerns with regard to detection bias is the lack of information reported on outcome assessment. When an outcome relies on the judgement of a clinician (the primary outcome of this study was described as a "qualitative medical assessment") and that clinician is aware of the allocation of the patient being assessed then interpretation of the clinical findings may be biased. Qualitative outcome measures such as this are of dubious validity anyway, especially when wound healing is relatively easy to measure objectively (by measuring time to complete healing or serial measures of wound size). In our opinion a better approach would be to present the actual reduction in area for each group along with confidence intervals to allow interpretation of the differences in healing and the associated precision.

We would welcome any information that might give us further clarity on how the outcome assessment was undertaken. Incidentally we are even more confused now given that your letter states that the evaluation was made after five weeks for the untreated Diapulse group and only three weeks for the Diapulse treated group. How could these assessments have been made at different times if the assessor was blinded? Why does the published paper state in the Abstract that there was is a maximum two-week treatment period; but in Tables 2, 3 and 4 that the duration of treatment was variously one, two, three, four, five, six and eight weeks!

From your data we calculated the relative risk (RR) for healing with Diapulse therapy. The Cochrane Collaboration recommends that RRs are produced for dichotomous data whenever the event rate is greater than $30 \%$. As you will be aware from reading the review the RR for healing in your trial was $10(95 \% \mathrm{Cl} 0.7$ to 143.7$)$. Whilst the result of this seems to favour the use of Diapulse therapy to heal pressure ulcers, the wide confidence intervals, which include 1, indicate a lack of statistical significance. Unfortunately your trial was extremely small, resulting in a lack of statistical power to detect a clinically important treatment effect as statistically significant (the result for the main comparison are consistent with a RR anywhere between 0.7 , i.e. in favour of conventional treatment, to 143.7 in favour of electromagnetic therapy). This together with the baseline difference in wound area means that whilst there may be a real treatment effect your trial does not provide convincing evidence of it.

Salzberg CA et al. The effects of non-thermal pulsed electromagnetic energy (Diapulse) on wound healing of pressure sores in spinal cord injured patients: A randomised double blind study. Wounds 1995; 7:1 11-16.

We were unable to obtain assurance of random sequence generation or allocation concealment from Salzberg's written report. The allocation process for people with Stage II ulcers did not result in a balanced allocation between the two treatment groups although this was corrected for in the analysis (whilst the statistical tests for differences were not significant the differences are not unimportant). The low power of the study, again due to low sample size, is compounded by the separation of Stage II and Stage III patients which is, in effect, a subgroup analysis. Such subgroup analyses should be pre-planned, and in this case it is severely underpowered, but is the basis of the "statistically significant" difference in the original report. No baseline data were provided for patients with Stage III pressure ulcers, therefore we were unable to judge the success of the randomisation. However, these patients account for $33 \%$ of the patients in the study and they are effectively lost from the overall analysis. Readers cannot exclude chance or bias as possible causes of the treatment difference. We calculated the RR of healing for people with Stage III pressure ulcers as 7 (95\% $\mathrm{Cl} 0.45$ to 108.26). Whilst this result is in the direction of benefit from Diapulse, there is no statistically significant difference.

The substantial questions about the internal validity of the two studies reviewed, and the small size of these studies, means that whilst both studies show results in the same qualitative direction (that of benefit of electromagnetic therapy), it would have been wrong to draw the conclusion that this is an effective treatment. This is clearly an important area for future high-quality research. Such research should involve sufficient numbers of patients to ensure a realistic chance of detecting important treatment effects, and should avoid the threats to validity so frequently observed in wound care trials. We would also urge that any further studies follow the internationally respected CONSORT statement for the reporting of RCTs.

As I am sure you are aware, the systematic reviews undertaken by the Cochrane Collaboration use an internationally agreed process, which includes pre-publication peer review of the review protocol and the finished review, and open peer review of the review at any time after publication. This peer review did not identify similar concerns to yours. I am afraid we are unable to change the conclusions of the Cochrane Review as requested.

\section{Contributors}

Professor Sorin Comorosan (Romania)

Professor Nicky Cullum (UK)

Ms Kate Flemming (UK)

\section{WHAT'S NEW}




\begin{tabular}{lll}
\hline Date & Event & Description \\
\hline 26 June 2015 & New search has been performed & Fifth update, new search \\
\hline 26 June 2015 & $\begin{array}{l}\text { New citation required but conclusions } \\
\text { have not changed }\end{array}$ & No new trials identified, no change to conclusions \\
\hline
\end{tabular}

\section{HISTORY}

Protocol first published: Issue 4, 1998

Review first published: Issue 4, 2000

\begin{tabular}{lll}
\hline Date & Event & Description \\
\hline 23 October 2012 & New search has been performed & Fourth update, new search, no new studies. \\
\hline
\end{tabular}

23 October $2012 \quad$ New citation required but conclusions No change to conclusions, one author stepped down from the rehave not changed

20 September $2010 \quad \begin{aligned} & \text { New citation required but conclusions } \\ & \text { have not changed }\end{aligned}$

20 September $2010 \quad$ New search has been performed Third update. For this third update new searches were carried out in June 2010. Four studies were added to the table of Excluded studies. A risk of bias assessment was completed. The reviewers' conclusions remain unchanged.

\begin{tabular}{lll}
\hline 11 August 2009 & Amended & Contact details updated. \\
\hline 29 April 2008 & Amended & Converted to new review format. \\
\hline 29 April 2008 & New search has been performed & $\begin{array}{l}\text { Second update. For this second update, new searches were un- } \\
\text { dertaken. No new studies were identified. The reviewers' conclu- } \\
\text { sions remain unchanged. }\end{array}$ \\
\hline 1 January 2006 & $\begin{array}{l}\text { New citation required but conclusions } \\
\text { have not changed }\end{array}$ & $\begin{array}{l}\text { First update. Substantive amendment. New review authors } \\
\text { joined the review team. }\end{array}$ \\
& $\begin{array}{l}\text { For the first update, new searches were carried out in October } \\
\text { 2005. No new studies were identified. One study was excluded. } \\
\text { The reviewers' conclusions remain unchanged. }\end{array}$ \\
\hline
\end{tabular}

\section{CONTRIBUTIONS OF AUTHORS}

ZA conducted the third and fourth update of this review, checked the search results for new studies, undertook the risk of bias assessment and revised the text.

SBS has contributed to all updates of this review with respect to selection of studies, methodological advice and editing the text.

\section{Contributions of editorial base}

Nicky Cullum: edited the review, advised on methodology, interpretation and content. Approved the review update prior to submission. Ruth Foxlee updated the search strategies for all databases, ran the searches, de-duplicated the output and checked the references.

\section{DECLARATIONS OF INTEREST}

Zoriah Aziz: none

Sally Bell-Syer: none 


\section{SOURCES OF SUPPORT}

\section{Internal sources}

- Department of Health Sciences, University of York, UK.

\section{External sources}

- NHS Health Technology Assessment Programme, UK.

- General Nursing Council of England and Wales Trust, UK.

- Department of Pharmacy, Faculty of Medicine, University of Malaya, Malaysia.

- Cochrane Infrastucture Award, NIHR/Department of Health (England), UK.

\section{N DEX TERMS}

\section{Medical Subject Headings (MeSH)}

Magnetic Field Therapy [ ${ }^{*}$ methods]; Pressure Ulcer [ ${ }^{*}$ therapy]; Randomized Controlled Trials as Topic; Wound Healing

\section{MeSH check words}

Female; Humans; Male 